\title{
Advanced Communications Satellite Systems
}

\author{
JOSEPH N. SIVO
}

\begin{abstract}
Demand for in-orbit capacity through the use of satellite systems will continue throughout the next two decades. The potential of the $30 / 20 \mathrm{GHz}$ frequency band for fixed satellite services will be exploited. However, many technology questions must be answered if the band is to be used commercially because of the high rain fades that can occur at these high frequencies.

NASA has conducted a technology development program in high gain antenna and on-board switching and processing systems which can be combined such that cost competitive services are possible at acceptable rain outage percentages. Other supporting technologies have also been pursued including transmitters, both tube type and solid state, and low noise receivers. The critical technologies have been combined into an experimental satellite payload; an experimental flight is planned to verify these technologies and enable development of operational systems. Implementation of such systems would be by commercial carriers and could occur in the early 1990's, depending on the demand for additional or bit capacity. The high capacity systems that can be made possible through the use of the $30 / 20 \mathrm{GHz}$ band and the employment of frequency reuse technology will contribute to the continued downward trend in circuit costs and may allow new and innovative satellite services.
\end{abstract}

\section{BACKGROUND}

$\mathrm{T}$ HE rapidly growing demand for satellite circuits, particularly for domestic service within the United States, has caused significant concern for the capability of satellite systems, as we know them today, to meet future demand. This was recognized within the telecommunications community as early as the mid-late 1970 's when various committees, technical societies, and government organizations urged that NASA reestablish its efforts in high risk satellite communications research and development (which had significantly phased down in 1973) to provide the advanced technologies necessary to expand the capabilities of future satellite systems to meet this growing demand. Official sanction to such research and development was given in a 1978 Presidential Directive PD-42 which directed NASA to resume its responsibility for advanced space communications technology. In cooperation with the National Research Council's Space Applications Board Subcommittee on Satellite Communications, whose membership was composed of leading common carriers, spacecraft manufacturers, and representatives of communications users, NASA's communications technology program was planned.

Manuscript received June 8, 1982; revised November 15, 1982.

The author is with the Space Communications Division, NASA Lewis Research Center, Cleveland, OH 44135.
NASA's current program is aimed at developing the high risk, advanced satellite communications technologies required to significantly increase the capacity of future satellite communications systems. The program includes both a broad technology development program focused on the critical technology elements and the definition of a suitable experimental flight system capable of verifying the readiness of the systems technology for operational system implementation. The technologies under development include multiple-beam spacecraft antennas, on-board switching and processing, RF devices and components, and advanced earth stations. They are applicable to multiple frequency bands in order to support a wide range of future communications systems required by NASA, other government agencies, and U.S. industry. The program is also aimed at opening up and exploiting higher frequency bands than those currently in use. For this reason, the technology program is focused on the Ka-band which is the next higher frequency band above the $\mathrm{C}$ - and $\mathrm{Ku}$-bands allocated for fixed domestic satellite service. The primary attraction of this band is the $2.5 \mathrm{GHz}$ allocated for satellite use, which is five times that of either the C- or Ku-bands.

At the outset of the program in 1978, parallel market studies were undertaken to determine the potential role of Ka-band satellite communications in the U.S. These studies confirmed earlier assessments that the rapidly increasing demand for domestic satellite communications services would probably saturate the orbit space and frequency allocations at $\mathrm{C}$ - and Ku-bands near the end of this decade.

This assessment was revised by NASA in 1980 (Fig. 1). It shows demand (expressed as equivalent $36 \mathrm{MHz}$ transponders) rising even faster than originally estimated in spite of projected improvements with time of the capability of transponders to handle more throughput. The capacity of a typical $(36 \mathrm{MHz})$ transponder has grown from a few hundred half circuits in the early 1970 's to 1000 or more today. Within the next decade, individual transponder capacities of up to 3000 half circuits are expected to be in operation by using advanced modulation, coding, and bandwidth compression techniques.

The estimated capacity limit of domestic satellites (DOMSATS) using C- and/or Ku-band frequencies (Fig. 1) was also increased from the earlier estimate of 430 transponders to about 1200 transponders. This increase reflected projected improvements in frequency reuse at $\mathrm{C}$ - 


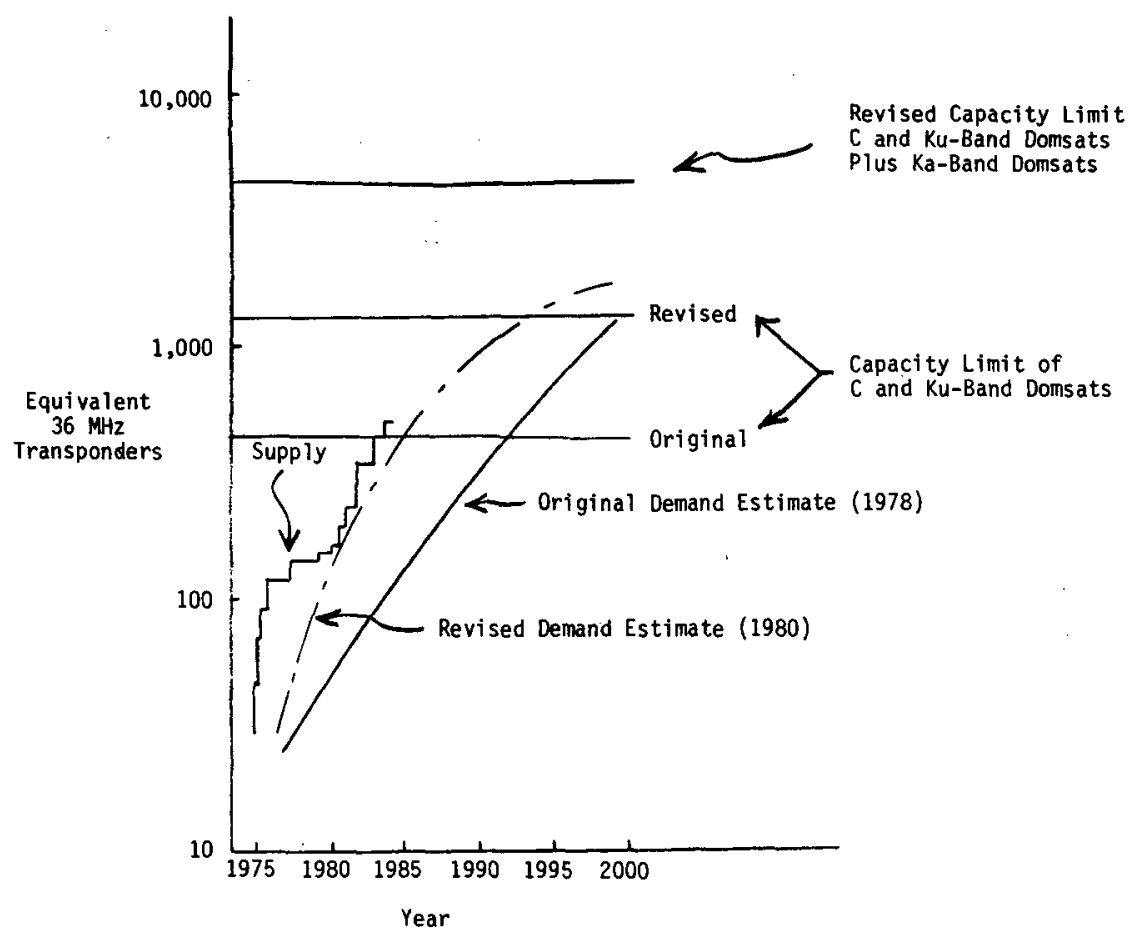

Fig. 1. U.S. domestic communications satellite demand and supply.

and Ku-bands. Even with these improvements, it may be seen from Fig. 1 that the $\mathrm{C}$ - and $\mathrm{Ku}$-bands will be saturated in the early 1990's. In fact, given today's orbit spacing constraints $\left(4^{\circ}\right.$ between $\mathrm{C}$-band satellites and $3^{\circ}$ between Ku-band satellites), the orbit space for existing plus planned $\mathrm{C}$-band DOMSATS is already saturated. Closer spacing is currently under consideration by the FCC (down to $2^{\circ}$ at C-band) and potentially offers additional orbit capacity but it is not expected that this would delay the onset of saturation by more than a few years.

There is considerable debate on when entirely new systems will be required to preclude such saturation and the resulting stagnation of industry growth. Obviously, projections of the future always contain considerable uncertainty. This uncertainty is heightened in the satellite communications industry because of its relative infancy and the tremendous potential that exists for new services and business opportunities, some of which have probably not yet been identified, if history is any guide. Because of this uncertainty, it was deemed necessary that NASA should undertake the current program of technology development focused at Ka-band. The added capacity offered by Kaband systems in the future will provide the necessary room for continual market growth to beyond the year 2000 (Fig. 1).

Studies of operational system concepts were also undertaken early in the program in parallel with the market studies. These studies were aimed at developing concepts for operational systems using Ka-band that could be cost competitive with systems operating at $\mathrm{C}$ - and $\mathrm{Ku}$-band frequencies. The studies addressed the traffic and its distribution, required satellite capacity, rain attenuation, satellite power requirements, configuration, and expected system costs in order to determine attractive satellite system concepts capable of providing the needed service. To accommodate the traffic as well as to compensate for the expected rain fades, trades were conducted considering uplink and downlink power requirements, coding, throughput requirements, spacecraft and ground terminal antenna gains, switching and processing schemes, fixed and scanning spot beams, and multiple-access techniques. The resulting satellite systems incorporated high gain spacecraft antenna systems with moderate transmitter powers and a combination of both fixed and scanning spot beams. Switching and processing on board the spacecraft provided the required interconnection among the many spot beams. The system capability was tailored to fit the expected skewed traffic distribution indicated in the market studies. In addition to the operational system concepts defined in the studies, the technologies critical to successful operation of the systems were also identified.

\section{Traffic Distribution and Service Scenario}

It was evident from the market study results that communications traffic is not uniformly distributed across the country. It is, in fact, highly skewed and is concentrated in major metropolitan areas. As a result, it is possible to serve a high percentage of the expected total traffic while illuminating only a small percentage of the land mass of CONUS. This skewed and highly concentrated traffic could be served with a multiple spot-beam satellite system where spot sizes of less than $0.5^{\circ}$ in diameter are used.

To illustrate the nature of the traffic distribution, Table I shows the percent of total communications traffic, addressable by satellite, associated with the top 45 traffic hubs in 
TABLE I

45 NODE TRAFFIC MODEL

\begin{tabular}{|c|c|c|c|c|c|}
\hline Rank & Node (Major City) & $\begin{array}{l}\text { Percent of Total } \\
\text { Long Haul Iraffic }\end{array}$ & Rank & Node (Major City) & $\begin{array}{l}\text { Percent of Total } \\
\text { Long Haul Traffic }\end{array}$ \\
\hline 1 & New York & 7.59 & 24 & Greensborough & 0.69 \\
\hline 2 & Los Angeles & 5.19 & 25 & Columbus & 0.66 \\
\hline 3 & Chicago & 4.27 & 26 & San Diego & 0.63 \\
\hline 4 & San Francisco & 3.18 & 27 & Phoenix & 0.62 \\
\hline 5 & Washington, D.C. & 2.65 & 28 & Tampa & 0.61 \\
\hline 6 & Boston & 2.55 & 29 & Portland & 0.52 \\
\hline 7 & Detroit & 2.39 & 30 & Buffalo & 0.52 \\
\hline 8 & Philadelphia & 2.33 & 31 & Salt Lake City & 0.46 \\
\hline 9 & Houston & 1.73 & 32 & Rochester & 0.46 \\
\hline 10 & Cleve I and & 1.59 & 33 & New Orleans & 0.45 \\
\hline 11 & Dallas & 1.44 & 34 & Lansing & 0.44 \\
\hline 12 & Minneapolis/St. Paul & 1.21 & 35 & Harrisburg & 0.44 \\
\hline 13 & Cincinnati & 1.18 & 36 & Norfolk & 0.43 \\
\hline 14 & Miami & 1.17 & 37 & Syracuse & 0.42 \\
\hline 15 & St. Louis & 1.13 & 38 & Oklahoma City & 0.40 \\
\hline 16 & Pittsburgh & 1.12 & 39 & Nashville & 0.40 \\
\hline 17 & At lanta & 1.09 & 40 & Fresno & 0.39 \\
\hline 18 & Hartford & 1.05 & 41 & San Antonio & 0.38 \\
\hline 19 & Denver & 0.84 & 42 & Louisville & 0.38 \\
\hline 20 & Milwaukee & 0.80 & 43 & Memphis & 0.36 \\
\hline 21 & Kansas City & 0.75 & 44 & Omaha & 0.36 \\
\hline 22 & Seattle & 0.74 & 45 & Jacksonville & 0.35 \\
\hline 23 & Indianapol is & 0.72 & & & \\
\hline
\end{tabular}

the U.S. These 45 hubs account for the traffic of 123 standard metropolitan statistical areas (SMSA) and 57 percent of the total inter-SMSA long-haul traffic.

Using a satellite with $400.3^{\circ}$ spot beams having the coverage area shown in Fig. 2, these 45 hubs could be interconnected (some hubs fall within the same beam). A geographical coverage area of only 15 percent is required.

It is of some interest to note what a typical service scenario might be for an operational system. For a 40 spot-beam system, the typical traffic distribution could be as shown in Table II. Major trunking services are provided among 18 fixed beam locations (open spots shown in Fig. 2) with a total traffic volume of 6 Gbits/s or about 100000 voice circuits. The beams carrying the highest trunking traffic must handle ten times the rate of throughput as the lightly loaded trunking beams. It is expected that terminal capacities would range from 550 to $88 \mathrm{Mbits} / \mathrm{s}$. For trunking, the number of terminals per beam is expected to be small, averaging less than two per beam.

For the lower traffic rates an additional 22 spots, as indicated by the shaded circles in Fig. 2, are needed in conjunction with the 18 trunking spots. These lower traffic spots will typically be served by relatively small terminals located on customers' premises, commonly referred to as customer premises service (CPS). The interconnection for this service would be accomplished using a scanning spotbeam system to permit time sharing of the spacecraft power among the service areas. The total traffic for this service is less than $4 \mathrm{Gbits} / \mathrm{s}$ or about 60000 voice circuits. The major difference between trunking and CPS is in the number of terminals per beam and the data rate per terminal. As many as 80 low data rate terminals per beam are possible in this latter system placing a high premium on acquiring low cost CPS terminals.
Operational requirements such as these drive the configuration. of the spacecraft system as well as the ground terminal system. They establish the goals of the technology associated with the major elements of the satellite system and, in the case of the NASA program, have led to the current technology development activity.

\section{Rain Attenuation}

The concerns with regard to rain fades at $30 / 20 \mathrm{GHz}$ occupy many discussions relative to the suitability of the band for commercial service. An example of rain attenuation at $20 \mathrm{GHz}$ (downlink) is shown by the statistics for Rosman, NC, shown in Fig. 3. The figure shows the percentage of time a given attenuation is exceeded for a single-station site and a two-station site. In the two-station case, the stations are separated by $10-15 \mathrm{~km}$ and are interconnected. In the presence of rain, the better of the two sites at any instant (the one experiencing lower attenuation) is used to provide an improvement in overall availability on the downlink for the site. For an availability of 0.999 , for example $(0.1$ percent on the vertical axis of Fig. 3), about $10 \mathrm{~dB}$ of downlink margin would have to be provided in the single-station case whereas only about 3.3 $\mathrm{dB}$ of margin would be required in the two-station case. The use of two stations per site is referred to as site diversity, and the improvement over a single site $(6.7 \mathrm{~dB}$ in this case) is often referred to as diversity gain.

Within CONUS, Rosman tends to be near the median for rain attenuation. Other sites can experience considerably more attenuation (e.g., Miami) or less attenuation (e.g., Los Angeles). The design of a Ka-band satellite system must take account of these varying statistics as well as provide for margins on both the uplink and downlink. 


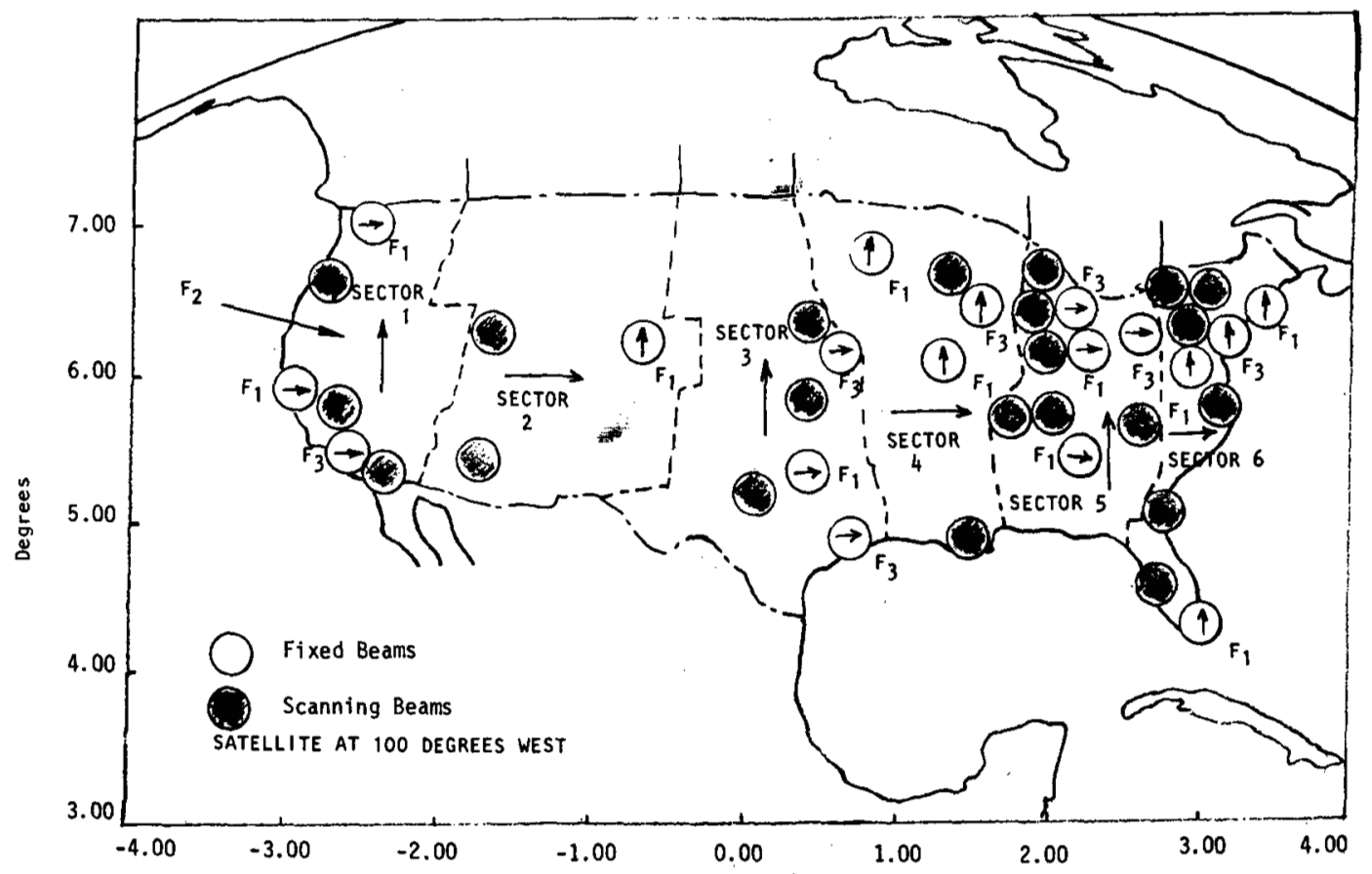

Fig. 2. Fixed beam and scanning beam frequency plan.

TABLE II

Traffic Characteristics for Large Satellite System

\begin{tabular}{|c|c|c|c|c|}
\hline SERVICE & $\begin{array}{l}\text { HO, OF BEAM } \\
\text { LOCATIONS }\end{array}$ & $\begin{array}{l}\text { TOTAL TRAFFIC } \\
\text { GBPS }\end{array}$ & $\begin{array}{l}\text { MAX. TO MII, } \\
\text { BEAM TRAFFIC }\end{array}$ & $\begin{array}{l}\text { NO. OF } \\
\text { TERMINALS }\end{array}$ \\
\hline $\begin{array}{l}\text { PA IOP. TRULFKING } \\
\text { VIA } \\
\text { FIXED BENHS }\end{array}$ & 18 & 6.0 & $10: 1$ & 33 \\
\hline $\begin{array}{c}\text { CPS } \\
\text { VIA } \\
\text { FIXED \& SCAM BEAMS }\end{array}$ & 40 & 4.0 & $9: 1$ & 2100 \\
\hline
\end{tabular}

Given the goal of providing an overall system availability of 0.9999 for trunking services in an operational system, analysis has indicated that site diversity would be required in most instances. Also, provision of $10 \mathrm{~dB}$ of margin on the downlink and $20 \mathrm{~dB}$ on the uplink should generally result in combined uplink plus downlink availabilities near 0.9999. Note that the individual uplink and downlink availabilities must be greater than 0.9999 to achieve a combined availability of 0.9999 (i.e., the product of the two).

The use of site diversity as a technique for rain fade compensation is not without penalty. Obviously the cost of the two stations and the interconnect system will be higher than for a single-station site. However, where high data rate trunking applications are considered, the number of terminals in the system is expected to be small and the total cost of the ground system is not dominant. The resulting impact of the higher site diversity costs on circuit costs may well be acceptable.

For the case where throughput rates of a given terminal are low, such as with CPS, the use of site diversity does not appear to be cost effective. The large number of terminals expected for this service dictates the use of low cost termi-

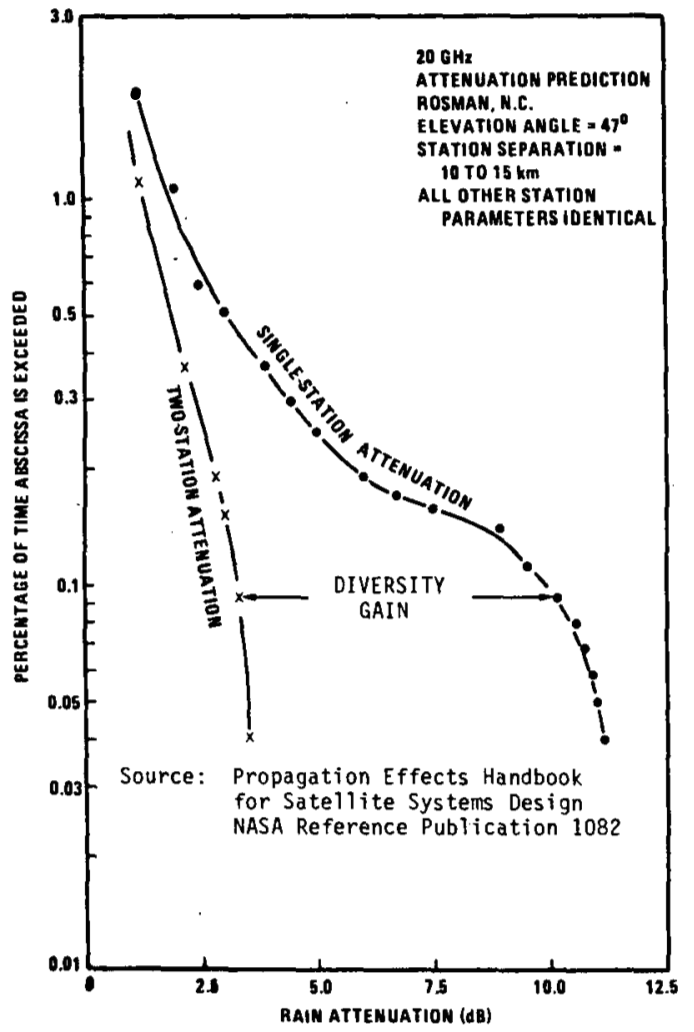

Fig. 3. $20 \mathrm{GHz}$ downlink attenuation.

nals. As a result, the approach to rain fade compensation must necessarily be different than that used in the trunking application. From a system operations viewpoint, a lower availability may be acceptable for these terminals. The use of forward error correction coding in conjunction with fixed power margins on both the uplink and downlink appears to offer an acceptable solution. Power margins of 3 $\mathrm{dB}$ on the downlink and $5 \mathrm{~dB}$ on the uplink are used in 
conjunction with a rate one-half convolutional coding having a constraint length of 5 and two-to-one reduction in the symbol rate. The combined margins provide a minimum availability of 0.995 which is acceptable for this type of service. Another possibility suggests itself because of the large number of terminals expected to be in the system. Cooperative arrangements between closely spaced CPS terminals could provide a means of diversity gain without the high cost of dedicated two-station sites.

\section{SYSTEM CONFIGURATION}

The satellite concept definition studies to date have identified several important factors inherent in the use of frequencies at $20 \mathrm{GHz}$ and above. It is well known that, as frequency increases, rain attenuation becomes an increasingly difficult problem to contend with if high circuit availability is required. Considering the effects of increased rain attenuation and higher operating noise temperature encountered at higher frequencies, a Ka-band system would typically require about $10 \mathrm{~dB}$ greater power than an equivalent area coverage Ku-band system for the same system availability of 0.995 . Increasing the desired availability results in requiring higher margins for $20 \mathrm{GHz}$ systems. For a given spacecraft data rate, attempting to compensate for the rain fade by only increasing power on the spacecraft does not appear to be economically viable. However, increasing the spacecraft antenna gain in concert with modest increases in spacecraft power appears to be an attractive compromise. The situation on the uplink is even more difficult with rain fade in dB's at $30 \mathrm{GHz}$, approximately double that at $20 \mathrm{GHz}$. Spacecraft antenna gains in the 50-55 dB range appear to offer a good compromise to power augmentation alone and help on both the uplink and downlink. Antenna gains of $55 \mathrm{~dB}$ will require spacecraft antennas of approximately $4 \mathrm{~m}$ in diameter (transmit at $20 \mathrm{GHz}$ ) and $3 \mathrm{~m}$ (receive at $30 \mathrm{GHz}$ ). The use of high gain spacecraft antennas results in spot-beam illumination of the service area. Multiple spot beams thus become necessary to provide broad service area coverage. However, as a consequence of the increase in expected rain fade at $30 / 20 \mathrm{GHz}$ compared to the lower, currently used satellite frequencies, provision of contiguous and simultaneous CONUS coverage even with spot-beam systems will likely require unacceptably high spacecraft powers. Therefore, less than complete CONUS coverage is desirable for these systems. In addition to the restricted area coverage, the use of multiple spot beams creates a beam interconnectivity problem; in order to minimize ground terminal complexity, the use of on-board switching and routing is necessary.

Although spot-beam systems are a significant complication when compared to single CONUS beam coverage, the existence of separated spot beams allows consideration of reuse of the same frequency in the spatially separated beams. This reuse potential when coupled with the wide bandwidth allocation permits the development of satellite systems having very large capacities per spacecraft. A distinct advantage of the high frequencies lies in the ability to generate the needed spot beams with antennas of mod- est physical size. This, in conjunction with the downscaling of all RF systems on the spacecraft, permitted by the higher frequencies, allows the construction of very high capacity satellites that require only modest weight and size increases when compared to current satellites. As a result, the potential cost per circuit may be considerably lower than current costs in spite of the added system complications.

Since the spacecraft antenna system will be a major element of advanced satellite system concepts, a look at antenna technology requirements is warranted. To establish the antenna coverage required in the 45 hub traffic scenario discussed earlier, a fixed beam pattern, illustrated in Fig. 2 by the open circles, coupled with the six scanning beam sectors, outlined by the dotted lines, is required. The specific locations to be visited by the scanning beams are shown as shaded circles within the scan sectors. A total of 18 fixed spots plus the 22 additional scan spots provides the 40 node coverage needed to serve the 45 communication traffic centers as mentioned earlier. A typical antenna system capable of providing the needed coverage is shown in Fig. 4. An offset main reflector system coupled with a subreflector is used. A beam, whether for fixed or scanning use, is formed by a radiating feed element or group of elements which illuminates a subreflector and then a main reflector. The offset configuration minimizes blockage by the feed assembly allowing improvements in sidelobe performance of the antenna. Off-axis scan performance requirements associated, for example, with forming east and west coast spot beams from the same antenna, dictate relatively large $F / D$ dimensions (about 2.0 based on the offset aperture diameter): For the fixed spot beams, there is generally adequate spatial separation of the beams to allow reuse of the same frequency in many of the beams. For the 18 fixed beams, a two-color (frequency) scheme is used, indicated by frequencies $f_{1}$ and $f_{3}$, to accommodate the closely spaced beams. Frequency $f_{1}$ can be used 11 times and $f_{3}$ can be used seven times. For the scanning beams, frequency $f_{2}$ is used with alternate polarization in adjacent sectors. A transmit and receive scanning beam operates in each sector. Each scanning beam system can visit a maximum of five or six spots during its scan. The potential frequency reuse coupled with the wide bandwidth allocated enable Ka-band satellite systems to have very large capacities. The creation of individual spot beams that are closely spaced, such as in the northeast corridor, requires feed sharing among the beams and is a technology driver.

An important and unique capability expected in advanced multibeam satellite systems is on-board satellite switching. In conventional satellite systems, messages must be switched to their destination by means of "groundbased" distribution networks. Message switching on the satellite will greatly simplify the ground system design and allow all terminals to talk to each other whether they are served by scanning or fixed beam systems. A time-division multiple-access (TDMA) technique is used for all satellite traffic. With the added complication of satellite switching, a master control terminal (MCT) is needed in the system to manage all satellite activity, including scheduling and message switching. The MCT assigns channels on the uplink 


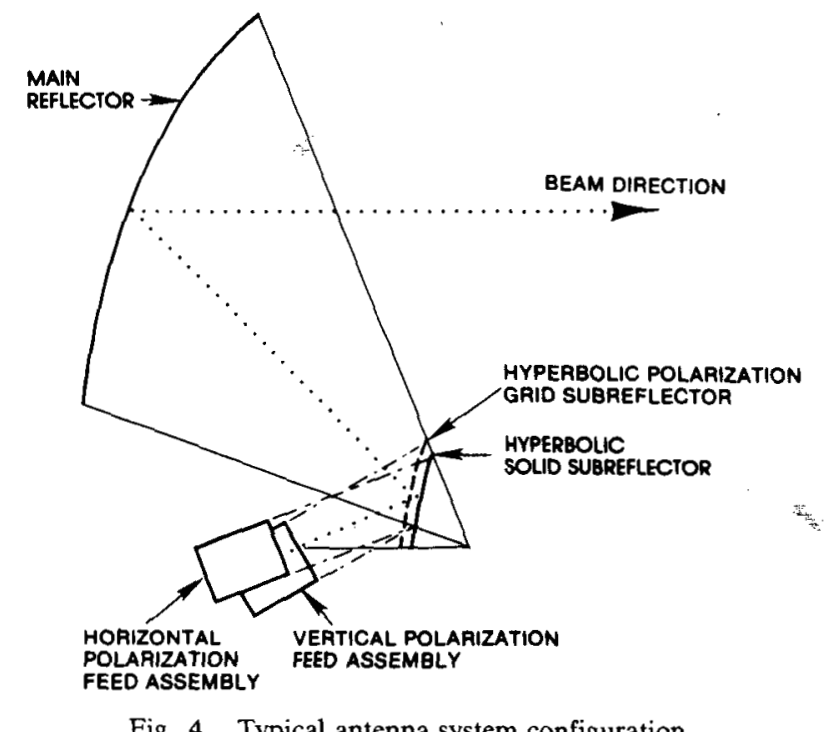

Fig. 4. Typical antenna system configuration.

beams, controls switching of messages within the satellite, and directs transmission of messages on the various downlink beams.

For trunking traffic among terminals in the 18 fixed beams, data bursts containing thousands of individual voice messages are formed according to destination and routed though the satellite under the control of the MCT. An on-board matrix switch permits connection of any uplink beam to any downlink beam as required. All the trunking terminals are fed to terrestrial distribution networks to permit routing of the individual voice calls to users. For the case in point, an $18 \times 18 \mathrm{IF}$ matrix switch would be used to facilitate the interconnections required. Multiple switch reconfigurations are required within a TDMA time frame to assure that data bursts received at the spacecraft from each uplink beam can be successfully routed to the proper downlink beam without interference. Switches having acceptable weight and power consumption are a technology driver.

For CPS type services, interconnection among all 40 spot-beam locations is required. Since each spot may contain up to 100 small terminals, the use of TDMA requires each terminal to burst in a controlled sequence in order to avoid interference between terminals. In contrast to trunking service where thousands of voice messages may be contained in a single burst, CPS terminal bursts containing five-ten voice calls are more common. Connection through the terrestrial network is avoided to minimize the cost of terrestrial tails. Therefore, messages must be routed to individual terminals on an individual voice call basis. The use of a matrix switch would require an excessive number of crosspoints in the switch making such routing impractical. Interconnectivity can be provided using a baseband processor to facilitate signal routing. The baseband processor under the control of the MCT accepts message bursts from both the fixed and scanning beams and stores the messages on board the satellite temporarily so that all data destined for a specific location are grouped together. At the proper time, the signals are read out of memory and transmitted as a burst down the proper downlink beam.
Since site diversity is not economically attractive with small CPS terminals, the baseband processor coupled with the CPS terminal provides an additional capability of forward error correction coding on both the uplink and downlink for rain fade compensation. The satellite baseband processor must be capable of handling tens of thousands of voice circuits with reasonable system weight and power. The processor, the matrix switch, and the multibeam antenna are the critical technologies of these advanced satellite system concepts.

\section{0/20 GHz TeChNOLOGy DEVELOPMENT APPROACH}

In an effort to minimize the risk associated with an experimental flight project using $30 / 20 \mathrm{GHz}$ hardware, NASA initiated a multidiscipline technology development program. Contracts were awarded to a broad spectrum of companies interested in $30 / 20 \mathrm{GHz}$ components and systems. The technologies being pursued are shown in Table III and include dual contracts for the multibeam antennas, matrix switches, low noise $30 \mathrm{GHz}$ receivers, and solid-state transmitters using both GaAs FET's and IMPATT's. Single awards were made for the baseband processor and the traveling-wave-tube $20 \mathrm{GHz}$ transmitter. Each of the contractors is required to develop proof-of-concept models of the specific technology. element using 1982 level technology. Breadboards of all critical components are required prior to POC model development. Completion of all contract activities was targeted for the end of 1982. The ground terminal technology contracts were initiated early in 1982 and will run for about two years. Two contracts for design studies of low cost TDMA-type terminals for CPS were awarded along with contracts for a solid-state IMPATT-type high power amplifier (HPA), a Karp circuit TWT for use in a tube-type HPA, and antenna proof-ofconcept model development. Completion of the proof-ofconcept model program will permit initiation of development of flight-qualified hardware for the experimental flight system.

\section{EXPERIMENTAL Flight SySTEM}

Earlier, a typical operational system was described having a very high capacity multibeam antenna system coupled with a matrix switch and a baseband processor. In an effort to establish the readiness of the technology, experimental system concepts were defined by NASA with the help, through parallel contracts, of the five commercial satellite system suppliers: Ford Aerospace, General Electric, Hughes, RCA Astro Electronics, and TRW. Implementation of the RF system was accomplished using 30 and $20 \mathrm{GHz}$ frequencies to reduce the associated hardware to manageable physical sizes and allow use of existing space-qualified spacecraft buses. A carrier working group made up of all the current satellite carriers reviewed and critiqued the range of system configurations studied and, based on their experience, provided recommendations to NASA on system requirements.

The resulting experimental system currently in the NASA plan embodies all of the critical technology elements necessary to test and verify the technology readiness of the 
TABLE III

TECHNOLOGY ELEMENTS AND SUPPLIES

\begin{tabular}{|c|c|}
\hline ACTLYLTY & PABLICIFALIS \\
\hline - BASEBAID PROCESSOR & WOTOROLA \\
\hline - LON NOISE RECEIVER & INTERNATINIAL TELEPHONE TELEGMPH; LNR \\
\hline - IMPATI TRANSMIIIER & LNR; TRH \\
\hline TWF & HUGuitS AIRCRAFT \\
\hline PPS/TWT INTEGRATION/RF TEST & TRW \\
\hline - GaA.s fet transmittier & IEXAS INSTRUMENTS; TRH \\
\hline - mitlibeam antenna system & FORD AEROSPACE; TRW \\
\hline - SHITCH MIRIX-TRUNKING & FORD AEROSPACE; GENERAL ELECTRIC \\
\hline \multicolumn{2}{|l|}{ - Loh cost earth station } \\
\hline DESIGN STUDY & TRW; FORD AEROSPACE \\
\hline ANTENHA & TBD \\
\hline IMPATT TRANSMITTER & TBD \\
\hline \multicolumn{2}{|l|}{ - COMHUHICATIOH SYSTEMS EVALUATIOH } \\
\hline SYSIEH COMPUTER SIMULATION & STANDORD TELECOMMUNICATIONS, INC. \\
\hline SYSTEM DEVELOPMENT \& IEST & LERC \\
\hline \multicolumn{2}{|l|}{ - SS-FDMA } \\
\hline SYSTEM STUDY & IHI IRE; GENERAL ELECTRIC \\
\hline ROUTING ASSERBLY & MOTOROLA \\
\hline
\end{tabular}

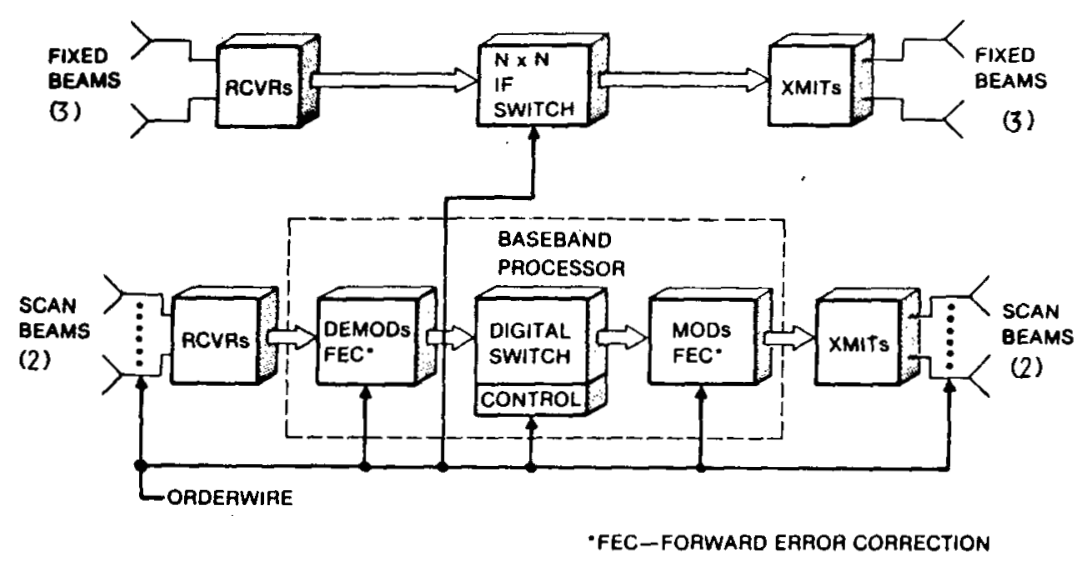

Fig. 5. Communications payload for experimental flight system.

concepts but with the necessary compromises made in throughput capacity and system flexibility. To minimize cost, a simplified transponder, typified by the spacecraft communications payload shown in Fig. 5, is planned. Three fixed spot beams for high data rate trunking are interconnected with an IF matrix switch. For the lower data rate systems, two scanning beams are used in conjunction with a baseband processor which employs demodulation, buffering, switching, and remodulation along with forward error correction to process messages to and from customer premise type terminals. The spacecraft transmit antenna is $3 \mathrm{~m}$ in diameter with a corresponding $2 \mathrm{~m}$ receive antenna which form $0.4^{\circ}$ spot beams having low sidelobes to permit demonstration of frequency reuse. A typical beam coverage pattern is shown in Fig. 6. Fixed spot beams are located on the east and west coasts to test the scan capability of the antenna and to provide varying environmental effects. Two adjacent scanning beam sectors are provided in the eastern third of the U.S. The burst rates for the trunking terminals are $240 \mathrm{Mbits} / \mathrm{s}$ using a $5 \mathrm{~m}$ ground antenna and an HPA of $400 \mathrm{~W}$. Site diversity with $12 \mathrm{~km}$ spacing between stations is planned. Maximum HPA power on the spacecraft is $40 \mathrm{~W}$. Power allowances of $18 \mathrm{~dB}$ on the uplink and $8 \mathrm{~dB}$ on the downlink are applied to the links experiencing rain to overcome attenuation. This should provide in excess of 0.999 availability on the trunking links. For the low data rate service, the spacecraft HPA is also $40 \mathrm{~W}$ with a throughput per beam of 120 Mbits/s provided in the two scanning beams. The channels per beam on the uplink can be either four $30 \mathrm{Mbit} / \mathrm{s}$ channels or one $120 \mathrm{Mbit} / \mathrm{s}$ channel. Ground terminal antenna diameters are $3 \mathrm{~m}$ and $5 \mathrm{~m}$ for the $30 \mathrm{Mbit} / \mathrm{s}$ and $120 \mathrm{Mbit} / \mathrm{s}$ systems, respectively. A combination of power augmentation and FEC on the uplink and downlink provides rain margins of $15 \mathrm{~dB}$ and $6 \mathrm{~dB}$, respectively. An availability in excess of 0.995 is expected. The TDMA system will employ closed-loop synchronization having a timing accuracy of about \pm 60 ns. An order wire system will be used in the network control scheme. Variations in subframe times and switch matrix configurations are possible as well as variations in scanning beam sequences and beam dwell times.

The overall primary experiment payload system weight is about $150 \mathrm{~kg}$ which permits use of either a SSUS-D or a SSUS-A class spacecraft bus launched by the shuttle. An artist's rendition of a typical spacecraft system is shown in Fig. 7. It employs three axis stabilization; however, spinning-type spacecraft bus systems are also suitable for the 


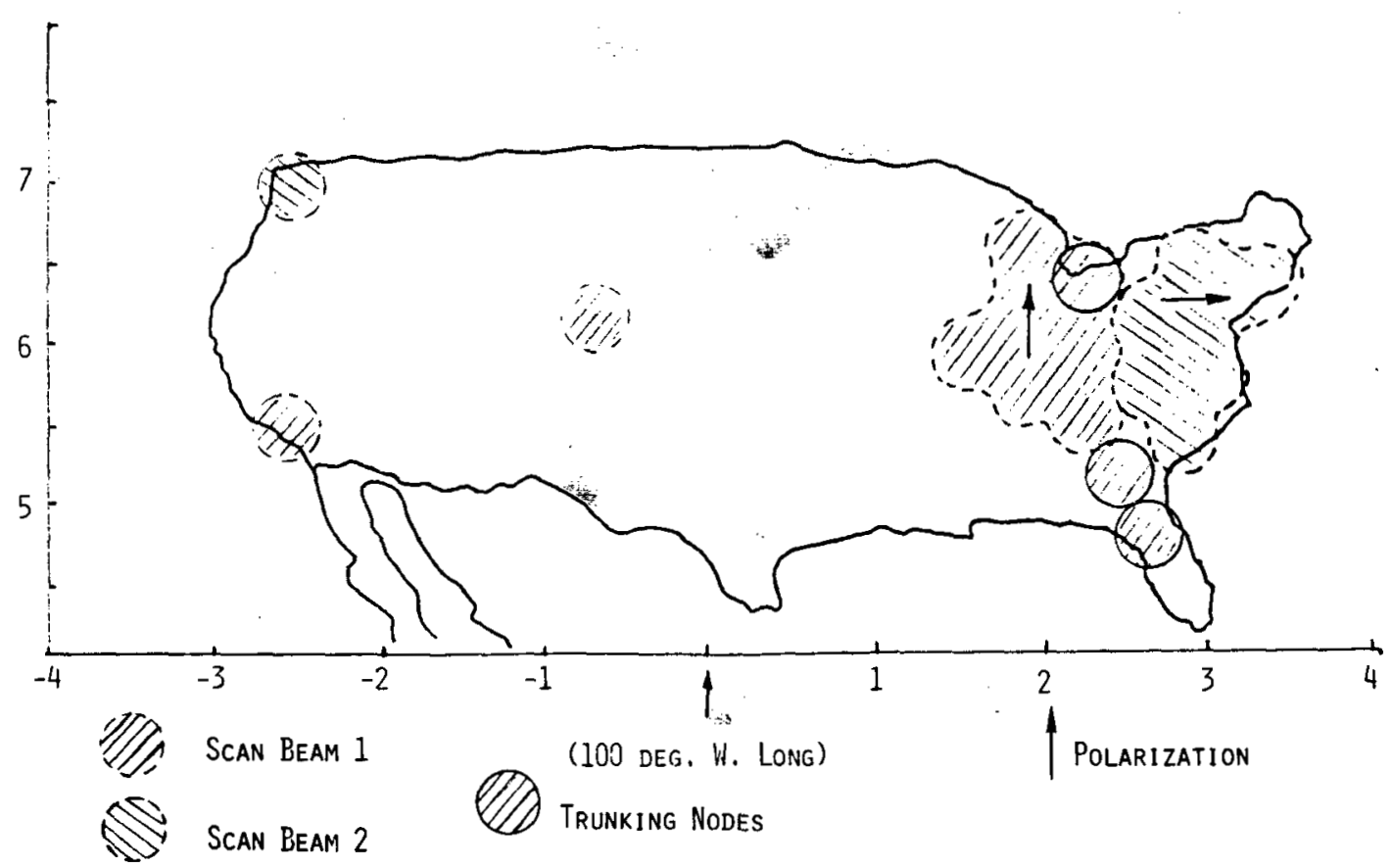

Fig. 6. Typical experiment flight system coverage.

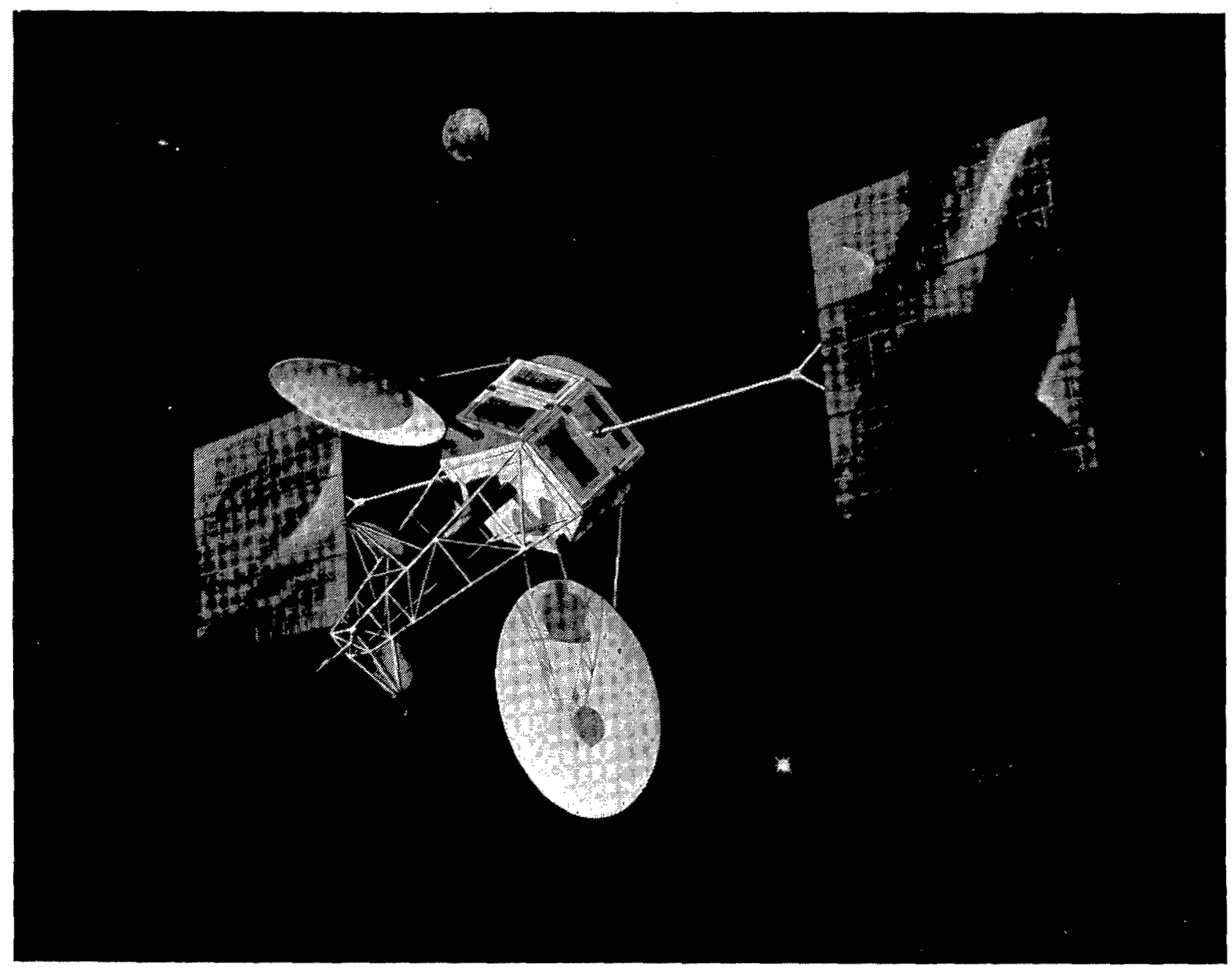

Fig. 7. Typical three axis stabilized flight spacecraft. 
experimental payload. Launch of the experimental system is under consideration by NASA and, if development is initiated in 1983, a launch could occur in late 1987 or early 1988. Excess satellite capacity will be assigned to ancillary experiment payloads on a noninterference basis. Candidate experiment payloads will be selected from a wide range of possible alternatives.

\section{a. SUMmary}

Continued demand for satellite circuits will require consideration of the use of the $30 / 20 \mathrm{GHz}$ band for fixed satellite communication service. Many technology questions remain with regard to system suitability to commercial service because of the high expected rain fades that will accompany the use of these high frequencies.

Technical advances in high gain multibeam antennas and on-board switching and processing hold promise that cost competitive systems with acceptable rain outages are possible. NASA's current technology development program is addressing the critical technologies that could make such systems successful. In addition, an experimental flight system to verify the technologies is being planned. Continuation of the NASA program will result in the enabling of the necessary technology such that the commercial carriers could implement operational systems at the $30 / 20 \mathrm{GHz}$ frequency bands as well as other bands in the early 1990 's. These advanced high capacity communication systems will continue the downward trend in circuit costs as well as usher in new and innovative satellite services.

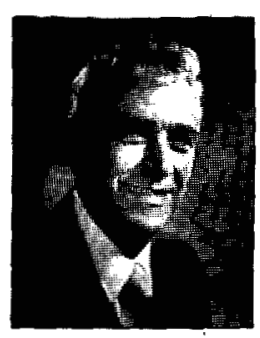

Joseph N. Sivo was born in East Hartford, CT. He received the B.S. degree in mechanical engineering from the University of Michigan, Ann Arbor, MI, in 1952.

He joined the National Aeronautics and Space Administration's Lewis Research Center in June 1952. He is presently serving as Chief of the Space Communications Division. From 1952 to 1958 he was engaged in aeronautical propulsion research at the Lewis Research Center, Cleveland, OH. When NACA became NASA; he was assigned to space related research and analysis in launch vehicle systems and space flight systems. In 1972 he was assigned to the satellite communications program at the Center and has participated in the Agency's communications research and development program including CTS and ATS satellites systems ever since. During this period he directed the disaster communications satellite studies conducted by NASA for NOAA and is currently responsible for NASA's emergency satellite communication activities. The Lewis Research Center was recently assigned lead responsibility for NASA's overall research and development program in satellite communications. He will lead that activity for the agency at the Lewis Research Center.

Mr. Sivo is a member of Tau Beta Pi and Pi Tau Sigma. 